\title{
The transfection of A20 gene prevents kidney from ischemia reperfusion injury in rats
}

\author{
LIXIN WEI $^{1}$, XIANGHUI ZHANG ${ }^{2}$, QIUPING YE ${ }^{1}$, YUEER YANG $^{1}$ and XIAOWEN CHEN ${ }^{1}$ \\ ${ }^{1}$ Department of Nephropathy, Union Hospital, Fujian Medical University, Fuzhou, Fujian 350001; ${ }^{2}$ Department of \\ Nephropathy, The Fifth Affiliated Hospital of Zunyi Medical University, Zhuhai, Guangdong 519000, P.R. China
}

Received April 22, 2016; Accepted March 24, 2017

DOI: $10.3892 / \mathrm{mmr} .2017 .6725$

\begin{abstract}
Ischemia/reperfusion may induce inflammation and cell death through the nuclear factor $(\mathrm{NF})-\kappa \mathrm{B}$ signaling pathway. As a negative regulator of $\mathrm{NF}-\kappa \mathrm{B}$, zinc finger A20 exhibits anti-apoptotic and anti-inflammatory effects in vitro. The present study was designed to upregulate A20 expression using an A20 transfection approach to investigate the in vivo protective effects of the $A 20$ gene on renal ischemia reperfusion injury. The $A 20$ gene was cloned into a pcDNA3.1 vector to construct the expression plasmid pcDNA3.1-A20. The plasmid was wrapped with a liposome and injected intravenously into rats $48 \mathrm{~h}$ prior to establishing the models of renal ischemia reperfusion injury. Saline and the empty plasmid pcDNA3.1 were used as controls. Following $24 \mathrm{~h}$ post-operation, A20 expression was determined using reverse transcription-quantitative polymerase chain reaction and western blotting. The renal function and structure were assessed by analyzing the concentrations of serum creatinine (Scr), blood urea nitrogen (BUN) and histological features. Renal tissues were additionally examined for renal tubular cell apoptosis and NF- $\kappa \mathrm{B}$ activity. The results demonstrated that in vivo transfection of pcDNA3.1-A20 induced renal A20 expression in rats. A20 overexpression in vivo significantly reduced renal injury as demonstrated by the improved levels of Scr and BUN and the reduction in histological damage. These improvements were accompanied by a suppression of renal proximal tubular epithelial cell apoptosis and an inhibition of NF- $\kappa \mathrm{B}$ activity. These results indicated that transfection of the $A 20$ gene upregulates the expression of A20 in vivo and protects the kidneys from ischemia reperfusion injury via inhibition of the $\mathrm{NF}-\kappa \mathrm{B}$ signal transduction pathway.
\end{abstract}

Correspondence to: Dr Lixin Wei, Department of Nephropathy, Union Hospital, Fujian Medical University, 29 Xinquan Road, Gulou, Fuzhou, Fujian 350001, P.R. China

E-mail: lixinwei66@126.com

Key words: kidney, ischemia reperfusion injury, zinc finger protein $\mathrm{A} 20$, cell apoptosis, nuclear factor- $\kappa \mathrm{B}$ signaling pathway

\section{Introduction}

Renal ischemia/reperfusion injury (IRI) is a primary cause of acute renal failure resulting from tubular dysfunction following shock, sepsis or renal transplantation (1). Despite various advances in vascular surgery, the rates of morbidity and mortality in patients with post-operative IRI remain particularly high (2). As with other pathological conditions of the kidney, renal ischemia may ultimately progress to chronic advanced kidney disease, which is characterized by tubule and capillary loss as well as regional interstitial fibrosis associated with chronic hypoxic stress (3-6).

In the ischemic kidney, and during the subsequent re-oxygenation, excessive reactive oxygen species (ROS) are generated in the reperfusion phase, initiating a cascade of deleterious cellular responses leading to inflammation, cell death and acute kidney failure (7). During the pathophysiological process, initiated in response to a broad spectrum of pro-inflammatory mediators including tumor necrosis factor (TNF)- $\alpha$, interleukin-1 and ROS $(8,9)$, nuclear factor (NF)- $\kappa \mathrm{B}$ is activated, mediating a vicious cycle of further inflammatory responses, which contribute to cell apoptosis. Therefore, targeting the $\mathrm{NF}-\kappa \mathrm{B}$ signaling pathway is a promising novel therapeutic strategy to inhibit the inflammatory and innate immune cascades responsible for the amplification of injury, which may produce effective treatments or prevention strategies for IRI. This concept was supported by a previous study that performed treatments with in vivo transfection of $\mathrm{NF}-\kappa \mathrm{B}$ decoy oligodeoxynucleotides, which significantly reduced the renal dysfunction and damage associated with ischemic acute renal failure (10).

Zinc finger protein A20 has been recognized as a central regulator of inflammation and apoptosis due to its ubiquitous inhibitory effect on $\mathrm{NF}-\kappa \mathrm{B}(8,11,12)$. As an $\mathrm{NF}-\kappa \mathrm{B}$ dependent gene, A20 forms a negative feedback loop, limiting $N F-\kappa B$ activation and inflammation in cells exposed to hypoxia and re-oxygenation $(8,13)$. Lee et al (14) reported that mice with A20 deficiency develop severe inflammation and cachexia as a result of failure to terminate the TNF-induced responses to $\mathrm{NF}-\kappa \mathrm{B}$ and cell death. Overexpression of A20 in rat kidneys using recombinant adenovirus-mediated gene transfer, protects rat kidneys from acute tubular necrosis following renal ischemia (13).

Therefore, the authors hypothesized that A20 may prevent the kidneys from IRI via a combination of anti-apoptotic and 
anti-inflammatory effects. The aim of the present study was to establish the A20 transfection model in rats and to evaluate the protective effect of in vivo A20 transfection on renal IRI by observing renal function, histopathological alterations, cell apoptosis and the $\mathrm{NF}-\kappa \mathrm{B}$ signaling pathway.

\section{Materials and methods}

Construction of recombinant human A20 expression plasmid. Human A20 cDNA was cloned into a pcDNA3.1 vector (Invitrogen; Thermo Fisher Scientific, Inc., Waltham, MA, USA) to construct the expression plasmid, which was termed pcDNA3.1-A20. The preparation of A20 cDNA and construction of pcDNA3.1-A20 were performed by the Invitrogen $\mathrm{Cn}$ Service (Project No: KL120515006; Shanghai, China). The plasmid DNA was transformed into $E$ coli DH5 $\alpha$ competent cells (Invitrogen; Thermo Fisher Scientific, Inc.) and grown in Luria Broth medium for propagation, according to the manufacturer's protocol. The plasmid DNA was subsequently extracted using the PureLink ${ }^{\circledR}$ HiPure Plasmid DNA Purification kit (Invitrogen; Thermo Fisher Scientific, Inc.) according to the manufacturer's protocol. The inserted sequences were digested with the restriction endonucleases NheI and XbaI (Promega Corporation, Madison, WI, USA) according to manufacturer's protocol, and verified by DNA sequencing, performed by the Invitrogen $\mathrm{Cn}$ Service, and separation by $1 \%$ gel electrophoresis.

Experimental animals. The animal experiments were approved by the Animal Ethics Committee of the Fujian University of Traditional Chinese Medicine (permit no. SCXK Shanghai 2012-0002; Fuzhou, China). Sprague-Dawley male rats (8-10 weeks in age and, 250-300 g in weight) were provided by the Laboratory Animal Center of Fujian University of Traditional Chinese Medicine. The rats received a standard diet, and were housed individually with free access to tap water. A $12 \mathrm{~h}$ light-dark cycle was provided. Room temperature was maintained at $21-23^{\circ} \mathrm{C}$ with $30-60 \%$ humidity. Rats $(n=24)$ were randomly assigned into three groups: Saline (control), plasmid control and A20 groups ( $\mathrm{n}=8$ /group). The three groups were given intravenous injections via the tail vein with saline (250 $\mu \mathrm{l})$, empty pcDNA3.1 plasmid (15 $\mu \mathrm{l}$ of Lipofectamine 2000 (Invitrogen; Thermo Fisher Scientific, Inc.) $+10 \mu \mathrm{g}$ of pcDNA3.1 mixed with saline to a final volume of $250 \mu \mathrm{l}$ ) or pcDNA3.1-A20 (15 $\mu \mathrm{l}$ of Lipofectamine $2000+10 \mu \mathrm{g}$ of pcDNA3.1-A20 mixed with saline to a final volume of $250 \mu \mathrm{l}$ ), respectively. Following $48 \mathrm{~h}$ post-injection, rats were anesthetized with sodium pentobarbital $(50 \mathrm{mg} / \mathrm{kg}$; Pitman-Moore Inc., Washington Crossing, NJ, USA) intraperitoneally. A ventral midline longitudinal incision $(8-10 \mathrm{~cm})$ was used to fully expose the left kidney, renal artery, abdominal aorta and vena cava. The renal ischemia reperfusion injury model was established by clamping the left renal artery and vein for $45 \mathrm{~min}$, then cutting the right kidney prior to reperfusion of the left renal vasculature. At $24 \mathrm{~h}$ post-operation, at the time of euthanasia, $2 \mathrm{ml}$ blood samples were drawn from the mesenteric vein and centrifuged at 1,500 x $\mathrm{g}$ for $10 \mathrm{~min}$ to obtain sera. For paraffin histologic assessments and cell apoptosis analysis, one part of the left kidney was fixed in $10 \%$ buffered formalin for $24 \mathrm{~h}$, the remaining parts of the kidneys were snap-frozen in liquid nitrogen for western blot, gene expression and electrophoretic mobility shift assay analyses.

Western blot analysis. Cytoplasmic and nuclear proteins were extracted using the Nucleoprotein Cytoplasm Protein Extraction kit (Nanjing KeyGen Biotech Co., Ltd., Nanjing, China) according to manufacturer's protocol. The protein concentration was measured using a Bicinchoninic Protein Assay (Beyotime Institute of Biotechnology, Shanghai, China) according to manufacturer's protocol. Proteins $(50 \mu \mathrm{g})$ were separated by $10 \%$ SDS-PAGE and transferred to nitrocellulose membranes. Following blocking in phosphate-buffered saline (PBS) containing 5\% skimmed milk overnight at $4^{\circ} \mathrm{C}$, the membranes were incubated with primary antibodies against A20 (dilution, 1:1,000; rabbit; 5630; Cell Signaling Technology, Inc., Danvers, MA, USA) and $\beta$-actin (dilution, 1:2,000; rabbit; 4970; Cell Signaling Technology, Inc.) for $2 \mathrm{~h}$ at room temperature. Bound antibodies were detected using an anti-rabbit horseradish peroxidase-conjugated secondary antibody (dilution, 1:5,000; goat; HS101-01; Beijing TransGen Biotech Co., Ltd.) for $1 \mathrm{~h}$ at room temperature. A chemiluminescent substrate (Thermo Fisher Scientific, Inc.) was used to detect the immunoreactive protein signals. Computerized image analysis was performed using Image $\mathrm{Lab}^{\mathrm{TM}}$ version 5.1 and a Molecular Imager ${ }^{\circledR}$ ChemiDoc $^{\text {TM }}$ XRS System (both from Bio-Rad Laboratories, Inc., Hercules, CA, USA). The values for the A20 protein were quantified and normalized to $\beta$-actin abundance. All samples were performed in duplicate.

$R N A$ isolation and reverse transcription-quantitative polymerase chain reaction ( $R T-q P C R)$. Total RNA was isolated from rat kidneys using TRIzol ${ }^{\circledR}$ (Invitrogen; Thermo Fisher Scientific, Inc.) and $5 \mu \mathrm{g}$ RNA was reverse-transcribed using the PrimeScript ${ }^{\mathrm{TM}}$ II First strand cDNA Synthesis kit (Takara Bio, Inc., Otsu, Japan) according to the manufacturer's protocol. The following primers for $A 20$ were designed to target the rat-specific mRNA region of the $A 20$ gene: Forward, 5'-CGG CGCTAGATTCTACGTCTTCA-3' and reverse, 5'-CTGTCT CGGATACTGCTTTGTCCA-3'. RT-qPCR was performed with the SYBR ${ }^{\circledR}$ Premix Ex Taq ${ }^{\mathrm{TM}}$ (Takara Bio, Inc.) following the manufacturer's protocol. Transcript levels were quantified by qPCR using the following cycling conditions: $3 \mathrm{sec}$ at $94^{\circ} \mathrm{C}$, then 40 cycles of $3 \mathrm{sec}$ at $95^{\circ} \mathrm{C}$ and $20 \mathrm{sec}$ at $60^{\circ} \mathrm{C}$. The expression levels of $A 20$ were normalized to the housekeeping gene ( $\beta$-actin: Forward, 5'-ACTTCGAGCAAGAGATGGC-3' and reverse, 5'-ACGTCACACTTCATGATGGA-3') and the initial amount of RNA used was calculated using the $2^{-\Delta \Delta \mathrm{Cq}}$ method as described previously (15). All samples were performed in duplicate.

Renal function assay. Renal function was detected by measuring serum creatinine (Scr) and blood urea nitrogen (BUN) using Raichem ${ }^{\mathrm{TM}}$ Enzymatic Creatinine Reagent and BUN Slow Rate Reagent (Cliniqa Corporation, San Marcos, CA, USA) according to the manufacturer's protocol, and measured on a Roche Automatic Biochemical Analyzer (Roche Diagnostics, Basel, Switzerland).

Histological analysis. One portion of the renal tissue was fixed in $10 \%$ buffered formalin for $24 \mathrm{~h}$. Following fixation 
and dehydration, sections $(4 \mu \mathrm{m})$ were cut and stained with haematoxylin and eosin for 1 min respectively at room temperature, followed by examination with a light microscope. Renal injury scores were determined by evaluating the degree of tubulointerstitial injury according to tubular necrosis, tubular dilatation and/or atrophy, inflammatory cell infiltration or cellar edema, as previously described (16): 0 , normal kidney; 1 , minimal necrosis $(<5 \%$ involvement of the cortex or outer medulla); 2 , mild necrosis (5-25\% involvement of the cortex or outer medulla); 3 , moderate necrosis (25-75\% involvement of the cortex or outer medulla); 4 , severe necrosis ( $>75 \%$ involvement of the cortex or outer medulla). Histologic examination was performed in a blinded manner by a renal pathologist using a light microscope (Zeiss AG, Oberkochen, Germany).

Evaluation of cell apoptosis. Cell apoptosis in the renal tissue sections $(5-\mu \mathrm{m})$, was quantified using a DeadEnd ${ }^{\mathrm{TM}}$ Colorimetric TUNEL System (Promega Corporation), according to the manufacturer's protocol. For all staining procedures, the terminal deoxynucleotidyl transferase dUTP nick end labeling (TUNEL)-positive cells were counted in 8 random high-power fields using a light microscope by two individual evaluators. Disagreements in results were resolved by a third evaluator.

Electrophoretic mobility shift assay (EMSA). The DNA binding activity of NF- $\kappa \mathrm{B}$ was assessed on nuclear extracts of kidney tissue, extracted as aforementioned, using a Chemiluminescent EMSA kit (Beyotime Institute of Biotechnology) according to the manufacturer's protocol. Radio-labeled $\mathrm{NF}-\kappa \mathrm{B}$ consensus oligonucleotide was incubated with $5 \mu \mathrm{g}$ nuclear extract in $10 \mu \mathrm{l}$ binding buffer at room temperature for $20 \mathrm{~min}$. The negative control reaction, cold probes competitive reaction and the mutant cold probe competitive reaction were also incubated with the same amount of samples as the controls and using the exact same experimental conditions. Band shifts were resolved on a non-denaturing 6.5\% polyacrylamide gel. Radiographic signals were quantified by densitometry using the Molecular imager ChemiDoc ${ }^{\mathrm{TM}} \mathrm{XRS}^{+}$ system with Image Lab ${ }^{\mathrm{TM}}$ software (Version 5.1, Bio-Rad Laboratories, Inc.).

Statistical analysis. The data were analyzed using SPSS 18.0 (SPSS, Inc., Chicago, IL, USA). Differences among multiple groups $(>2)$ were assessed using one-way analysis of variance, followed by the post hoc Tukey-Kramer test. The data differences between two groups were analyzed by an unpaired Student's t-test. $\mathrm{P}<0.05$ was considered to indicate a statistically significant difference. Data are presented as mean \pm standard deviation or as the median (range).

\section{Results}

A20 expression in renal tissue. The recombinant pcDNA3.1-A20 plasmid was constructed successfully as demonstrated by DNA sequence and restriction enzyme analyses (Fig. 1). Subsequently the plasmid DNA was wrapped by a liposome and transfected into the rats. As expected, transfection with the pcDNA3.1-A20 significantly increased

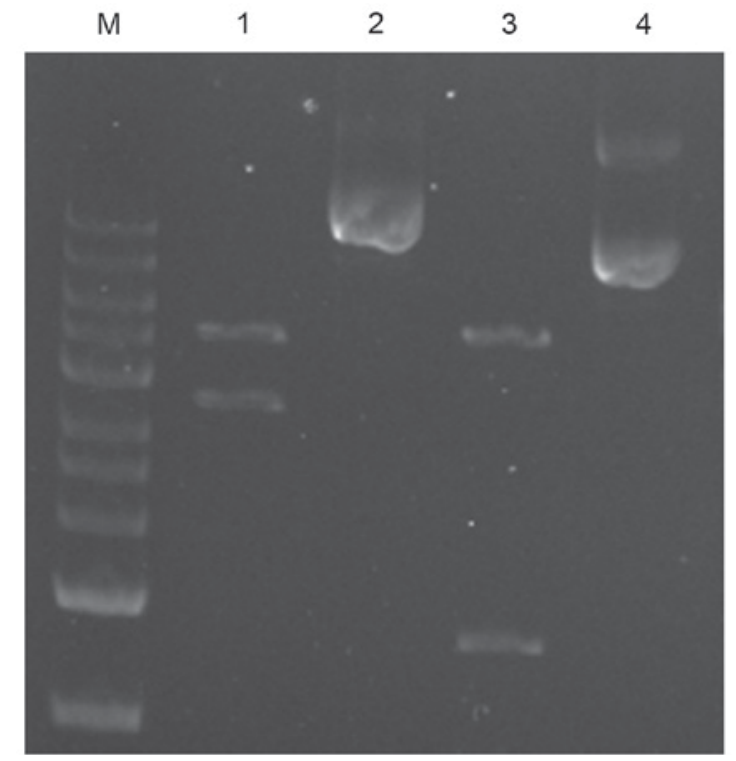

Figure 1. Plasmid DNA electrophoresis patterns. The plasmid DNA was verified by $1 \%$ agarose gel electrophoresis. M, DNA Ladder (1kb); lane 1 pcDNA3.1-A20 digested by $\mathrm{NheI}$ and $\mathrm{XbaI}$ restriction endonucleases; lane 2, pcDNA3.1-A20; lane 3, pcDNA3.1 digested by NheI and XbaI restriction endonucleases; lane 4, plasmid pcDNA3.1.

\section{A}

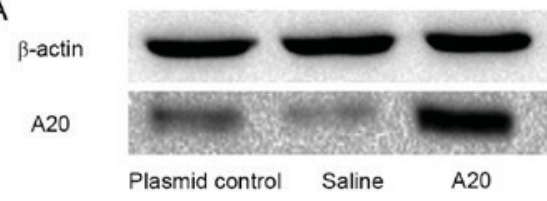

B

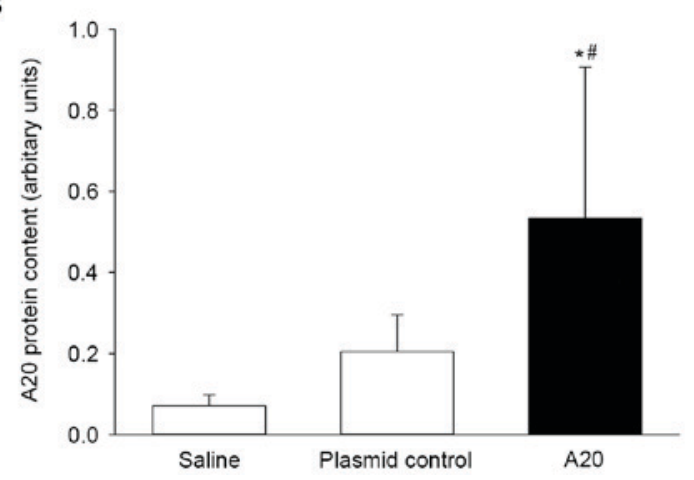

Figure 2. A20 protein expression in renal tissue. (A) Western blotting illustrated the expression of the A20 protein in cytosolic fractions using representative samples from each group. (B) A20 protein expression in the saline control, empty plasmid transfected and A20 transfected groups ( $\mathrm{n}=7 /$ group). Data are presented as the mean \pm standard deviation. ${ }^{*} \mathrm{P}<0.05$ vs saline control; ${ }^{~} \mathrm{P}<0.05$ vs. plasmid control.

the cytoplasmic A20 protein expression in vivo (Fig. 2). When compared with the saline group, the $\mathrm{A} 20$ protein level increased 7-fold following $72 \mathrm{~h}$ of A20 transfection $(\mathrm{P}<0.05)$. Although the concentration of A20 appeared to be elevated in the animals transfected with the plasmid control, when compared to the saline control the difference was not statistically significant $(\mathrm{P}>0.05)$. The A20 mRNA level was further quantified in the three experimental groups, however, no significant differences were identified in mRNA expression of A20 between groups ( $\mathrm{P}>0.05$; Fig. 3 ). 


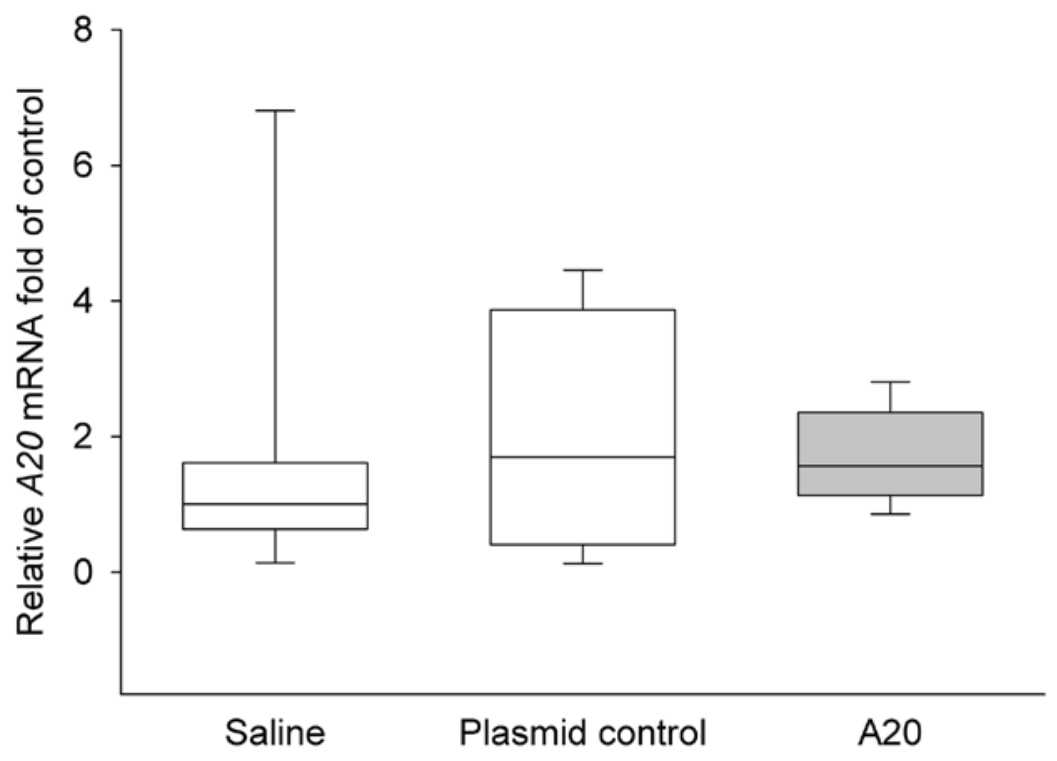

Figure 3. A20 gene expression in renal tissue. The A20 gene expression in the saline control ( $\mathrm{n}=8)$, empty plasmid transfected (n=8) and A20 transfected groups $(n=9)$. The box and whisker plots depict the median and the 10 and 90 th centiles.
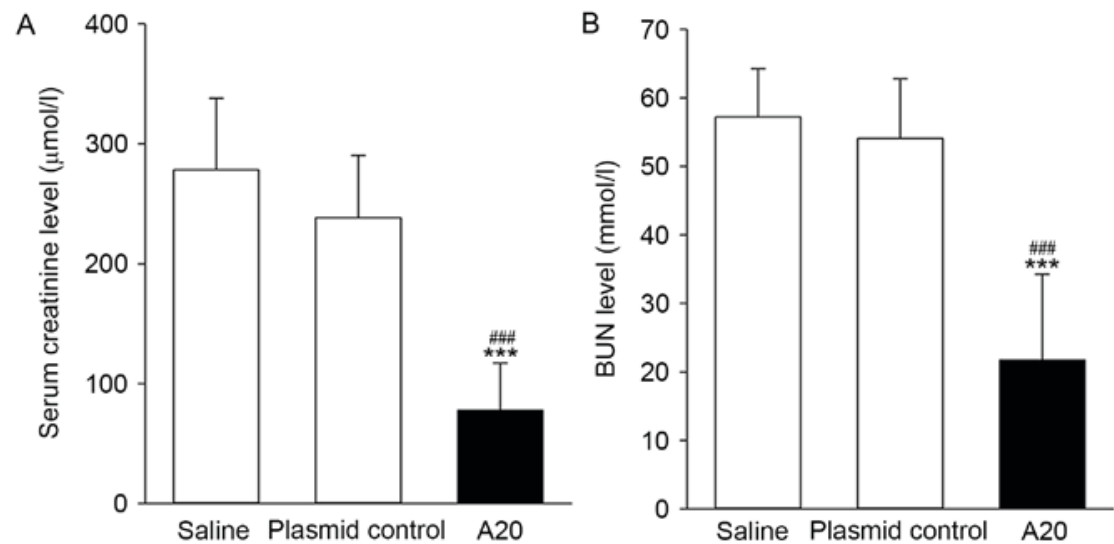

Figure 4. Serum Scr and BUN. The levels of (A) Scr and (B) BUN in the three groups. Data are presented as the mean \pm standard deviation (n=8/group) ${ }^{* * * *} \mathrm{P}<0.001$ vs. saline control; ${ }^{\# \# \#} \mathrm{P}<0.001$ vs. plasmid control. Scr, serum creatinine; BUN, blood urea nitrogen.

Renal injury. The present study determined the levels of the renal injury indicators, Scr and BUN following IRI. When compared with the animals pretreated with pcDNA3.1 or saline, overexpression of A20 induced an $\sim 3$-fold decrease in the levels of Scr and BUN (P<0.001; Fig. 4). The extent of renal tissue damage following IRI was evaluated using the histological approach. The saline and plasmid control groups exhibited a similar degree of pathological damage (Fig. 5), including, renal tubular dilatation, cracks in cells and cells flattening, injured tubular epithelial cells or loss of brush border, tubular epithelial cell shedding or necrosis and protein casts or cell debris observed in the tube cavity, and tubular epithelial cell shedding was observed to be the most serious feature. Conversely, in the A20 group, damage to the tubular epithelial cells brush border was the fundamental alteration. However, changes in renal glomerulus structures, including the endothelial cell lining and basement membrane, were not significantly different amongst the three groups. When analyzing the tubular damage scores, the A20 group was significantly lower compared with the two control groups $(\mathrm{P}<0.05$; Fig. 5).

Renal tubular epithelial cell apoptosis. The number of apoptotic cells in the kidney tissues of experimental rats was determined using a TUNEL assay. Apoptotic cells were primarily present in the renal tubules, particularly in the distal tubule, while few were identified in the renal interstitium and glomerular. The number of TUNEL-positive cells was significantly lower in the A20 group $(56.25 \pm 26.47)$ when compared with the saline group $(109.25 \pm 49.91)$ at $24 \mathrm{~h}$ of IRI $(\mathrm{P}<0.05$; Fig. 6). In addition, the total number of apoptotic cells accumulated in the renal tubular epithelium was similar between the groups administrated saline or empty plasmid control.

Analysis of NF- $\kappa B$ DNA-binding activity. A significant reduction in nuclear DNA binding activity of NF- $\mathrm{KB}$ was observed in the experimental rats transfected with pcDNA3.1-A20. This 


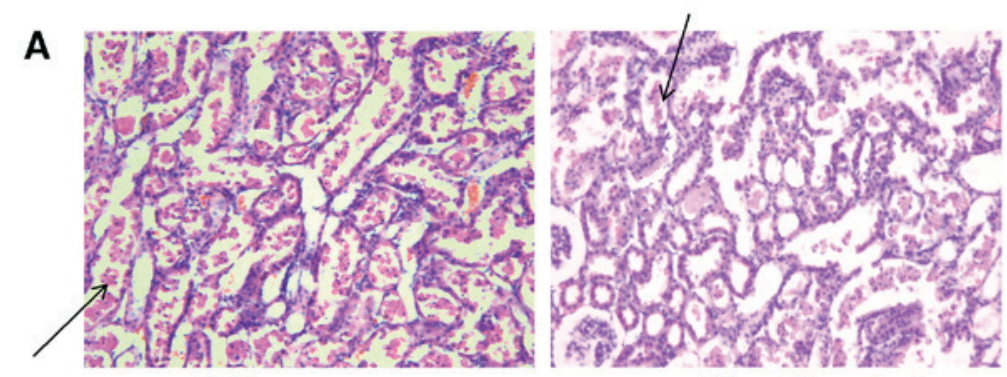

Saline
Plasmid control

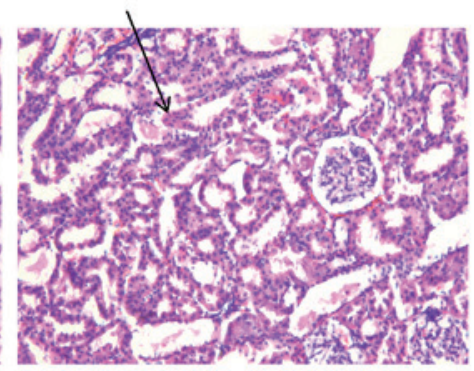

A20

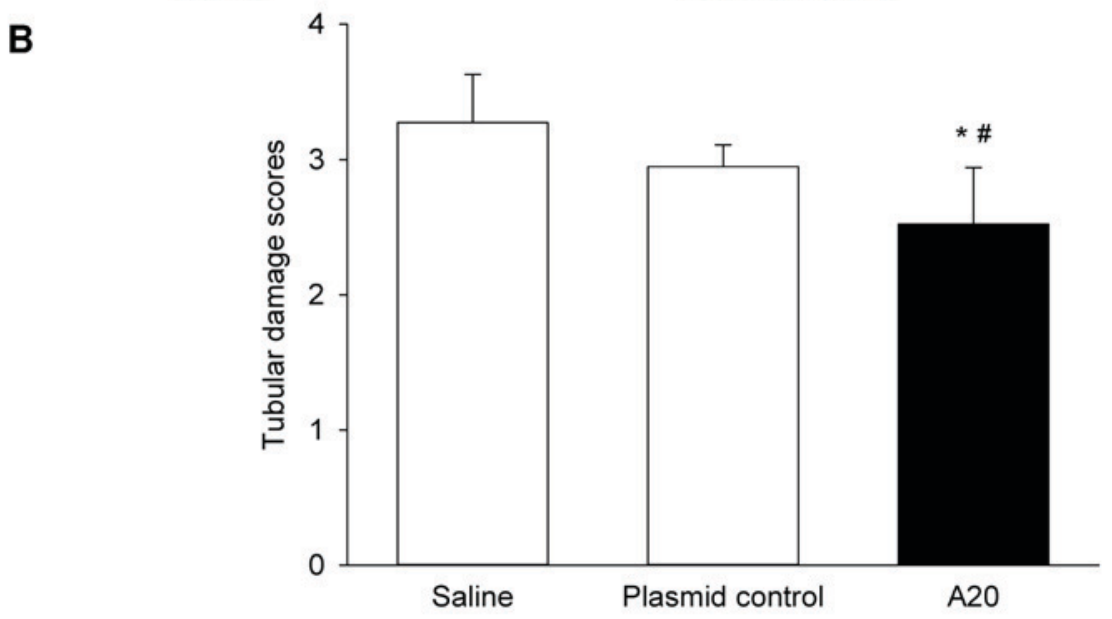

Figure 5. Histological characteristics in renal tissue. (A) Hematoxylin-eosin staining revealed the pathological alterations in the representative samples from each group. (B) The tubular damage scores in the three groups. Magnification, $x 200$. Data are presented as the mean \pm standard deviation ( $=8 /$ group). Arrows indicate injured renal tubular epithelial cells. ${ }^{*} \mathrm{P}<0.05$ vs. saline control; ${ }^{\#} \mathrm{P}<0.05$ vs. plasmid control.

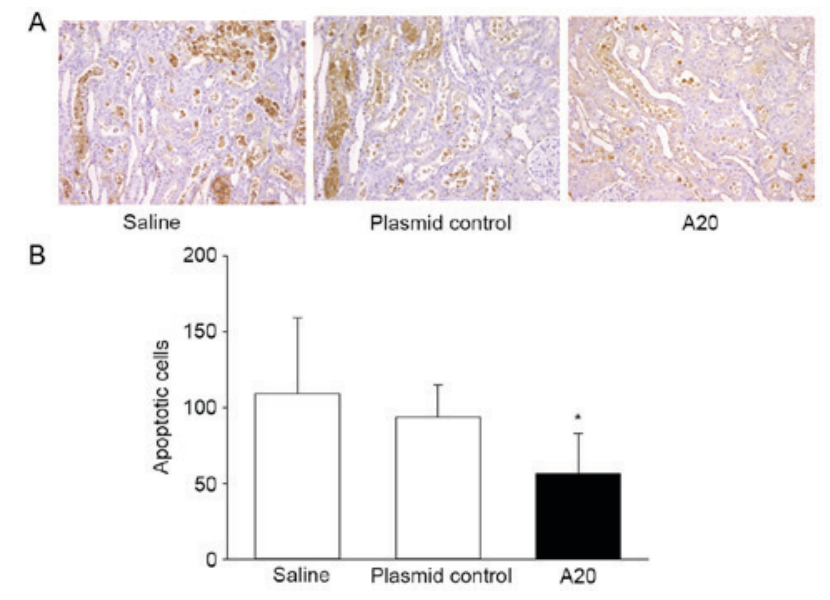

Figure 6. Detection of apoptotic cells in renal tissue. (A) Microscopic examination revealed the number of apoptotic cells present in renal tissues from the representative samples of each group. (B) The number of TUNEL-positive apoptotic cells in the three groups. Magnification, x200. Data are presented as the mean \pm standard deviation ( $\mathrm{n}=8$ /group). ${ }^{*} \mathrm{P}<0.05$ vs. saline control.

activity was reduced in the A20 group by 53\% when compared with the plasmid control group $(\mathrm{P}=0.001$; Fig. 7).

\section{Discussion}

In the present study, a liposomal pcDNA3.1-A20 plasmid was successfully transfected into rats and a transient expression of A20 was produced in kidney tissues. Overexpression of

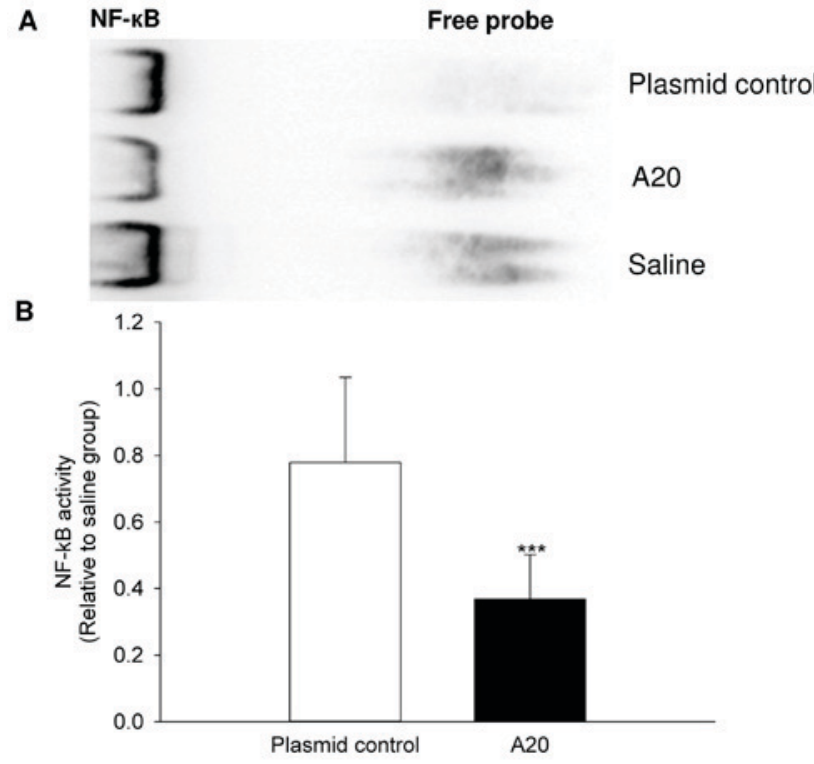

Figure 7. Nuclear NF-kB activity in renal tissue. (A) The band shift assay determined the activity of the signaling molecule NF- $\kappa B$ in nuclear fractions using representative samples from each group. (B) NF-kB activity in the plasmid control and A20 groups. Data are presented as the mean \pm standard deviation, expressed as the fold-change relative to the saline control group ( $\mathrm{n}=8$ /group). ${ }^{* * * *} \mathrm{P}<0.001$ vs. plasmid control group. NF- $\kappa \mathrm{B}$, nuclear factor- $\kappa \mathrm{B}$.

A20 attenuated renal injury, improved histological features, decreased cell apoptosis and inhibited $N F-\kappa B$ activation in 
this rat model of renal IRI. Collectively, these results suggest that transfection of the $A 20$ gene may be a simple and highly efficient method of protecting the kidneys from renal IRI.

To evaluate the therapeutic potential of the $A 20$ gene, a liposome-encapsulated plasmid DNA was used for gene delivery as this method is a reliable and simple technique for gene transfection $(17,18)$. Notably, non-viral transfection methods have the advantage of safe application with minimal risk of replication or viral incorporation and a lower chance of immunological rejection. In addition, plasmid DNA can be produced stably and at a low cost, to a high level of purity. As demonstrated by the western blot analysis, in vivo delivery of the liposome pcDNA3.1-A20 complex promoted A20 protein expression in kidney tissues $72 \mathrm{~h}$ following injection, suggesting that this method of delivery may be an efficient way of upregulating A20 expression in vivo. In contrast to A20 protein expression, the A20 mRNA expression levels did not demonstrate a significant change $72 \mathrm{~h}$ following transfection. This apparent discrepancy may be due to transient A20 gene expression induced by pcDNA3.1-A20 and differences in mRNA and protein turnover rates.

The present study determined whether A20 overexpression protected rat kidneys from IRI by conducting renal function tests and observing histological alterations. Increased blood levels of Scr and BUN are indicators of renal injury. The results indicated that A20 transfection markedly decreased the Scr and BUN levels following IRI. In response to IRI, the pathological damage was primarily evident in tubular epithelial cells. This damage was localized to the epithelial cells brush border following A20 treatment, and the tubular injury scores were attenuated. These results provided evidence of the beneficial effect of A20 transfection on renal IRI.

The functional and morphological improvement in the A20 group is likely to be attributable to the inhibitory effect of A20 on NF- $\kappa$ B activation and the resulting suppression of cell apoptosis. Activation of $\mathrm{NF}-\kappa \mathrm{B}$ occurs rapidly in response to ischemia/reperfusion in a number of tissues including kidney cells, brain, liver and myocardium (9,19-22). A20, as a key negative regulator of $\mathrm{NF}-\kappa \mathrm{B}$, exhibits anti-inflammatory and anti-apoptotic effects in cultured cells via inhibition of $\mathrm{NF}-\kappa \mathrm{B}(11,12,23)$. In the rat model of the present study, the number of apoptotic cells was significantly reduced in animals pretreated with pcDNA3.1-A20. In addition, a large proportion of TUNEL-positive cells were predominantly observed in the distal tubular epithelium in response to renal IRI, coinciding with the morphological features observed. The nuclear $\mathrm{NF}-\kappa \mathrm{B}$ binding activity was examined to analyze $N F-\kappa B$ signaling. Under normal conditions, $\mathrm{NF}-\kappa \mathrm{B}$ is retained in the cytoplasm by binding to its specific inhibitor protein, inhibitor of $N F-\kappa B$ (I $\kappa \mathrm{B})$. Upon stimulation, I $\mathrm{B}$ B is phosphorylated, degraded and is subsequently separated from NF- $\kappa$ B. The activated $N F-\kappa B$ is then translocated into the nucleus to activate transcriptional expression of downstream genes associated with inflammatory responses and apoptosis $(21,24)$. The results demonstrated that A20 transfection resulted in a $53 \%$ reduction in $\mathrm{NF}-\kappa \mathrm{B}$ DNA-binding activity, further confirming the efficacy of this in vivo transfection model and explaining the protective mechanisms of A20 in renal injury.

In conclusion, the results demonstrated that the liposome-encapsulated plasmid DNA vector for gene delivery upregulated the expression of A20 in vivo, conferring protection against IRI which was mediated by $\mathrm{NF}-\kappa \mathrm{B}$. These results offer a potential prophylactic treatment strategy for renal injury and support the use of A20 as a potential therapeutic target in renal IRI. However, further studies are required to assess whether there are side effects in other tissues, including the liver and heart, due to the systemic delivery of A20.

\section{Acknowledgements}

The present study was supported by the Natural Science Foundation of Fujian Province (grant no. 2010J0101).

\section{References}

1. Agrawal M and Swartz R: Acute renal failure. Am Fam Physician 61: 2077-2088, 2000

2. Giulini SM, Bonardelli S, Portolani N, Giovanetti M, Galvani G, Maffeis R, Coniglio A, Tiberio GA, Nodari F, De Lucia M, et al: Suprarenal aortic cross-clamping in elective abdominal aortic aneurysm surgery. Eur J Vasc Endovasc Surg 20: 286-289, 2000.

3. Basile DP: Rarefaction of peritubular capillaries following ischemic acute renal failure: A potential factor predisposing to progressive nephropathy. Curr Opin Nephrol Hypertens 13: 1-7, 2004.

4. Basile DP, Donohoe D, Roethe K and Osborn JL: Renal ischemic injury results in permanent damage to peritubular capillaries and influences long-term function. Am J Physiol Renal Physiol 281: F887-F899, 2001.

5. Bonventre JV and Weinberg JM: Recent advances in the pathophysiology of ischemic acute renal failure. J Am Soc Nephrol 14: 2199-2210, 2003

6. Nangaku M: Chronic hypoxia and tubulointerstitial injury: A final common pathway to end-stage renal failure. J Am Soc Nephrol 17: 17-25, 2006.

7. Malek M and Nematbakhsh M: Renal ischemia/reperfusion injury; from pathophysiology to treatment. J Renal Inj Prev 4: 20-27, 2015.

8. Beyaert R, Heyninck K and Van Huffel S: A20 and A20-binding proteins as cellular inhibitors of nuclear factor-kappa B-dependent gene expression and apoptosis. Biochem Pharmacol 60: 1143-1151, 2000.

9. Matsui N, Kasajima K, Hada M, Nagata T, Senga N, Yasui Y, Fukuishi $\mathrm{N}$ and Akagi M: Inhibiton of NF-kappaB activation during ischemia reduces hepatic ischemia/reperfusion injury in rats. J Toxicol Sci 30: 103-110, 2005.

10. Cao CC, Ding XQ, Ou ZL, Liu CF, Li P, Wang L and Zhu CF: In vivo transfection of NF-kappaB decoy oligodeoxynucleotides attenuate renal ischemia/reperfusion injury in rats. Kidney Int 65: 834-845, 2004.

11. Cooper JT, Stroka DM, Brostjan C, Palmetshofer A, Bach FH and Ferran C: A20 blocks endothelial cell activation through a NF-kappaB-dependent mechanism. J Biol Chem 271: 18068-18073, 1996.

12. Longo CR, Arvelo MB, Patel VI, Daniel S, Mahiou J, Grey ST and Ferran C: A20 protects from CD40-CD40 ligand-mediated endothelial cell activation and apoptosis. Circulation 108: 1113-1118, 2003

13. Lutz J, Luong le A, Strobl M, Deng M, Huang H, Anton M, Zakkar M, Enesa K, Chaudhury H, Haskard DO, et al: The A20 gene protects kidneys from ischaemia/reperfusion injury by suppressing pro-inflammatory activation. J Mol Med (Berl) 86: 1329-1339, 2008 .

14. Lee EG, Boone DL, Chai S, Libby SL, Chien M, Lodolce JP and Ma A: Failure to regulate TNF-induced NF-kappaB and cell death responses in A20-deficient mice. Science 289: 2350-2354, 2000.

15. Partridge J, Carlsen H, Enesa K, Chaudhury H, Zakkar M, Luong L, Kinderlerer A, Johns M, Blomhoff R, Mason JC, et al: Laminar shear stress acts as a switch to regulate divergent functions of NF-kappaB in endothelial cells. FASEB J 21: 3553-3561, 2007.

16. Furuichi K, Wada T, Iwata Y, Sakai N, Yoshimoto K, Kobayashi Ki K, Mukaida N, Matsushima K and Yokoyama H: Administration of FR167653, a new anti-inflammatory compound, prevents renal ischaemia/reperfusion injury in mice. Nephrol Dial Transplant 17: 399-407, 2002 
17. Nicolau C, Le Pape A, Soriano P, Fargette F and Juhel MF: In vivo expression of rat insulin after intravenous administration of the liposome-entrapped gene for rat insulin I. Proc Natl Acad Sci USA 80: 1068-1072, 1983.

18. Levine RM, Pearce TR, Adil M and Kokkoli E: Preparation and characterization of liposome-encapsulated plasmid DNA for gene delivery. Langmuir 29: 9208-9215, 2013.

19. Kis A, Yellon DM and Baxter GF: Role of nuclear factor-kappa B activation in acute ischaemia-reperfusion injury in myocardium. Br J Pharmacol 138: 894-900, 2003.

20. Donnahoo KK, Shames BD, Harken AH and Meldrum DR Review article: The role of tumor necrosis factor in renal ischemia-reperfusion injury. J Urol 162: 196-203, 1999.
21. Nichols TC: NF-kappaB and reperfusion injury. Drug News Perspect 17: 99-104, 2004.

22. Shen WH, Zhang CY and Zhang GY: Antioxidants attenuate reperfusion injury after global brain ischemia through inhibiting nuclear factor-kappa B activity in rats. Acta Pharmacol Sin 24: 1125-1130, 2003.

23. Zou XL, Pei DA, Yan JZ, Xu G and Wu P: A20 overexpression inhibits lipopolysaccharide-induced NF-kappaB activation, TRAF6 and CD40 expression in rat peritoneal mesothelial cells. Int J Mol Sci 15: 6592-6608, 2014.

24. Mazière $\mathrm{C}$ and Mazière $\mathrm{JC}$ : Activation of transcription factors and gene expression by oxidized low-density lipoprotein. Free Radic Biol Med 46: 127-137, 2009. 